\title{
Unifying global pandemic preparedness efforts
}

\author{
Jesús A. Siller-Farfán ${ }^{1,2, *}$ and Stephanie Gaglione ${ }^{3, *, \S}$ \\ Edited by Stephanie R. Smelyansky and Friederike M. C. Benning
}

\section{HIGHLIGHTS}

- Global frameworks for pandemic preparedness, such as the International Health Regulations, require stronger commitments from all nations.

- High-income countries can participate fully in existing international regulations and prioritize donor funding for health capacity strengthening in other countries.

- Low- and middle-income countries can continue to bolster national health systems and source sustainable long-term funding for their programs.

The COVID-19 pandemic illustrates the need for pandemic preparedness to be considered a global rather than a national metric. The 2005 International Health Regulations and supporting policy provide a foundation for building pandemic preparedness and health security in all countries. Examining the engagement of high-income, middle-income, and low-income countries in existing policies and programs, each income group can redress different challenges. With improved engagement in international regulations, targeted donor programs by high-income countries, and strengthened core health capacities in middle- and low-income countries, global pandemic preparedness is possible within the existing policy landscape.

\section{Foundations}

n 2019, the United States (U.S.) and the United Kingdom (U.K.) topped the Global Health Security Index, a global ranking for pandemic preparedness [1]. Less than one year later, both countries suffered high SARS-CoV-2 death rates. Thailand and Sweden ranked equally on the index; yet, at pandemic peak, Thailand reported 80 deaths per million inhabitants while Sweden reported over 800 . Why did COVID-19 pandemic outcomes correlate so poorly with

\footnotetext{
${ }^{1}$ Sir William Dunn School of Pathology, University of Oxford, Oxford, U.K.

${ }^{2}$ EPSRC and BBSRC Centre for Doctoral Training in Synthetic Biology, Doctoral Training Centre, University of Oxford, Oxford, U.K.

${ }^{3}$ Department of Chemical Engineering, Massachusetts Institute of Technology, Cambridge, MA

*Equal contribution

§Email: gaglione@mit.edu

S.G. is a former consultant of the WHO Department of Immunization, Vaccines, and Biologicals. The authors declare no other conflicts of interest.

(C) 2021 The Author(s)
}

preparedness rankings? How can we redefine what it means to be prepared for a pandemic? To prevent the next pandemic, we can define preparedness as a global goal rather than solely a national one.

Highly transmissible pathogens cross borders regardless of a country's national pandemic preparedness plan. If few other countries are prepared, pathogens spread more easily and demand more of a country's preparedness system. In a connected world, pandemic preparedness can be considered equal parts national and global. Countries should both build strong national preparedness systems and support a global, coordinated effort to ensure all countries reach a minimum preparedness standard.

Our review illustrates the current landscape of policy for pandemic preparedness and identifies global shortfalls. The International Health Regulations (IHR) constitute the foundation of our discussion on the current state of pandemic preparedness policy (Box 1). Recognizing that approaches to pandemic preparedness are similar for countries of the same income group, we segment our discussion by economic classification: high-income versus middle- and low-income economies (HICs, MICs, LICs). For purposes of this work, we use the World Bank country classifications by income level [2]. As of July 1, 2020, Gross National Income per capita is less than USD 1,036 for LICs, between USD 1,036 and USD 12,535 for MICs, and greater than USD 12,535 for HICs [2] We discuss opportunity areas for each group. Our work confirms that all income groups have opportunities to address unique shortfalls and that a strong, active collaboration between HICs, MICs, LICs, and central coordinating groups is key to global pandemic preparedness.

\section{Role of high-income countries in international pandemic preparedness}

HICs register above-median scores for adequate access to health-care services, essential medicines, and vaccines, in line with the United Nations (UN) Sustainable Development Goals $[4,5]$. Healthcare is also a budget priority for these nations: health-related government expenditure averages $17.8 \%$ in HICs that belong to the Organisation for Economic Co-operation and Development (OECD), compared to only 9.8\% for LICs part of the International Development Association (IDA) [6]. In principle, one could assume that these high scores and the significant, stable healthcare expenditures would positively correlate with pandemic 


\section{Box 1 - History of the IHR}

The origins of the IHR can be traced to the International Sanitary Regulations (ISR), which were adopted in 1951 by the World Health Assembly (WHA). The ISR was one of the first frameworks focused on the prevention of infectious diseases, namely yellow fever, smallpox, relapsing fever, cholera, typhoid, and plague. The IHR, first adopted in 1969 by the WHA, superseded the ISR. Further amendments in 1973 and 1981, as well as smallpox eradication in 1980, meant that the IHR would only cover three diseases: yellow fever, plague, and cholera.

In 1995, the WHA called for a substantial reform of the 1969 IHR. The WHA noted that the existing regulations had a narrow scope, as they only covered the three infectious pathogens described above. Although countries had closed borders since the early 1800 s to limit the spread of epidemics, the further growth of trade and the emergence of SARS in 2002 acted as a catalyst for the much-needed reforms of the IHR [3]. In 2003, the WHA established an intergovernmental working group that was in charge of drafting a new version of the IHR. The current version (2005) was approved by the WHA on May 23, 2005, and it went into effect by the middle of 2007 . Today, the IHR are legally binding for 196 countries, including all 194 members of the World Health Organization (WHO). As its second article states, the purpose of the IHR is to "prevent, protect against, control and provide a public health response to the international spread of disease" (1).

preparedness. However, the devastating effects of the COVID-19 pandemic in HICs such as the U.S. and most of Western Europe indicate that this is not the case. As of July 31,2021 , the death toll in the U.S. has reached 613,000 [7]. Estimates for the 2020 Gross Domestic Product (GDP) losses amount to USD 500.6 billion, indicating a decrease of $3.5 \%$ in real GDP compared to 2019 [8]. As a reference, a 2017 World Bank report had estimated that HICs such as the U.S. would only see annual GDP losses of $\sim 1 \%$ as a result of an active pandemic [6].

Since pandemic preparedness can be an umbrella term without a concrete definition, we can start by considering the existing frameworks for global health security. The IHR provide a legally binding foundation for all World Health Organization (WHO) members to prevent, control, and coordinate responses against pathogens with the potential to cross borders. In this respect, the IHR establish requirements in surveillance, core public health capacities, and early notification to the WHO of events that could become public health emergencies of international concern.
The evaluations from the Global Health Security Index (2019) suggest that, for the most part, HICs do possess adequate capabilities for ensuring interconnected and real-time reporting systems [1]. However, it is not clear that such capabilities translate to tangible benefits for other members of the $\mathrm{WHO}$. Indeed, in the context of the current pandemic, the $\mathrm{WHO}$ has issued calls for member states to increase the sharing of data according to the responsibilities established in the IHR [9].

Reluctance to share data with the WHO can stem from fears of suffering economic losses. Consider, for example, the economic impact in Canada due to the 2003 SARS outbreak, a country that suffered a GDP loss of approximately USD 3.2-6.4 billion despite having less than 300 cases [10]. This problem is exacerbated by the fact that, after a public health emergency of international concern is declared, it is not uncommon for countries to unilaterally implement additional restrictions beyond those issued by the WHO against affected countries. According to Article 43 of the IHR, such measures can only be conducted if they are supported by scientific principles and scientific evidence of risks to human health (1). For example, instances such as Canada's unilateral decision to suspend visa processing for foreign nationals in Ebola-affected countries during the 2014-2016 outbreak have been called into question [11]. This can strain bilateral relations between countries and undermine the overall authority of the WHO. Moreover, it is unclear whether unilateral travel restrictions are even capable of delaying the arrival of infections to other countries [12]-[14]. Therefore, the IHR could be updated to consider incentives, in the form of insurance payouts, for early notification of public health risks. We note that, although legally binding, non-compliance does not result in any sanctions or penalties. As far as is practicable, the IHR could be revised to consider disincentives and enforcement mechanisms against parties that repeatedly act in defiance to this legislation.

The principles of collaboration and assistance are enshrined in Article 44 of the IHR, and the recommendations of the WHO underline the importance of funding and supporting those countries that would benefit from technological and financial support (1) [15]. The role of some HICs as donors and supporters for health and development is acknowledged by the WHO [16]: overall, donor funding for preparedness represents a significant amount of the total Official Development Assistance (ODA) offered by OECD members. An analysis by the World Bank indicated that in 2015, the U.S. provided USD 2.48 billion $(7.8 \%$ of their total ODA) (Fig. 1) for pandemic preparedness [6]. Similarly, the U.K. provided USD 522 million, representing $6.2 \%$ of their ODA [6]. The Development Assistance Committee consists of $30 \mathrm{HIC}$ donors and strategizes the disbursement of ODA. To maximize the benefits of these donor funds, HICs could coordinate with the WHO to ensure that these funds are earmarked to ensure that all countries comply with the core capacities for surveillance, reporting, and response against potential outbreaks detailed in Annex 1 of the IHR (1). Where 
feasible, further development funds can be dedicated to address deficiencies noted in Joint External Evaluation (JEE) reports, which are voluntary assessments of each nation's capacity to prevent and mitigate public health crises.

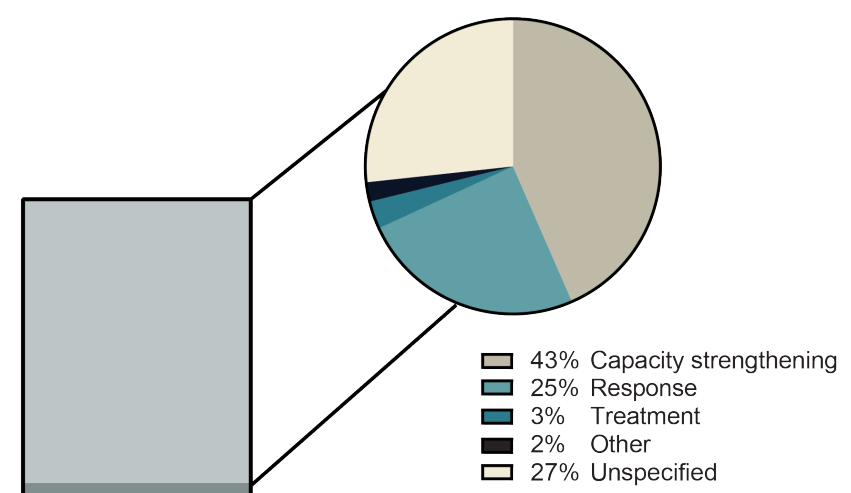

Sub-total = USD 1,512 million

ㅁ $38 \%$ Research and development

口 $63 \%$ Preparedness

Total = USD 2,485 million

Figure 1: U.S. donor funding for preparedness, excluding HIV, as part of their Official Development Assistance (ODA). Data reflects 2015 current USD. Source: 2017 report on Financing Pandemic Preparedness, World Bank. Data from Box 5.1 and Annex to Chapter $5[6]$.

Importantly, collaboration between countries can go beyond financial transfers, especially when pandemics are beginning to surge. For example, during the $2009 \mathrm{H} 1 \mathrm{~N} 1$ influenza pandemic, acquisition of vaccines by the UN was hampered by purchase agreements between HICs and manufacturers [17]. LICs and MICs are likely to consider this type of situation particularly aggravating, as they contribute many of the influenza strains to the Global Influenza Surveillance and Response System, with immediate benefits being reaped only by HICs and/or those countries that can domestically produce influenza vaccines [17]. The 2011 Pandemic Influenza Preparedness (PIP) framework attempted to address grievances of this nature [18]. However, unlike the IHR, the PIP framework is not legally binding. Moreover, the PIP framework is solely limited to influenza and fails to establish concrete commitments from HICs for issues related to intellectual property and vaccine sharing with LICs and MICs [18]. In this respect, the PIP framework could be enhanced to cover pathogens beyond influenza (e.g. SARS-CoV-1, SARS-CoV-2, MERS), address the deficiencies in equitable distribution, and acquire a legal standing similar to that of the IHR.

To further support collaboration between the WHO and $\mathrm{HICs}$, countries can consider enshrining the principles of the IHR in national legislation. This can be helpful in order to establish responsibilities and empower national organizations to fulfill the IHR within the existing legislative architectures. The WHO has already developed a framework for helping countries adopt the IHR in their national systems [19]. As of 2009 , only a handful of countries have included explicit provisions in their legal system to implement the IHR. As an example, the Health Protection Agency (Amendment) Regulations 2007, a statutory instrument of the U.K., requires the Health Protection Agency to send to the WHO communications related to new public health emergencies of international concern (2). Other countries, like Belgium, have outright decided to integrate the IHR in full into their legislation (3). A formal implementation of these regulations could address some of the reservations of the U.S. against the IHR. Currently, the U.S. is the only federal republic that has issued reservations against the IHR, indicating that the federal government is not legally bound by any IHR-imposed obligations that would fall under the jurisdiction of state governments.

In summary, HICs could benefit from re-evaluating their stances with the $\mathrm{WHO}$ and becoming regional leaders in health security. Concrete ways of achieving this include maintaining an open communication with the WHO, thus ensuring that their advanced surveillance and reporting capabilities translate into tangible benefits to all nations. Moreover, HICs should refrain from undertaking unilateral actions in contravention to the IHR, and be open to establish stronger collaborations with LICs and MICs beyond the mandates of the IHR and the PIP. In the medium and long term, a substantial reform of the IHR could be conducted, as it currently lacks enforcement mechanisms and does not acknowledge the existing disparities in vaccine procurement and distribution [20]. We recognize that such an endeavor will require complex negotiations and political will from all stakeholders, but it is clear that the COVID-19 pandemic illustrates the urgent need for reform.

\section{Improving health systems in middle- and low-income countries to boost pandemic preparedness}

Fragile health systems are the central limit to pandemic preparedness in middle- and low-income countries. JEEs are the starting point for identifying the preparedness deficiencies in each country. In contrast with HICs, LICs and MICs have largely complied with IHR reporting requirements. The number of countries submitting JEEs and allowing external evaluations of their health systems improved from 55 in 2018 to 102 in 2019 , including 45 of 48 African countries [21]. This represents substantial progress toward building basic health systems.

Although LIC and MIC participation in JEE reporting is commendable, the evaluations reveal massive gaps in all 19 technical health capacities defined by the IHR. MICs and LICs compose the $25 \%$ of all countries without the national capacity to prevent, respond, and control an outbreak [22]. No country in WHO's African region meets all 19 required capacities and the variance between countries is high [23]. Figure 2 compares the scores for 13 core IHR capacities between high-, middle-, and low-income countries. The only notable point of progress is pathogen detection, with all countries 
having some semblance of system to detect outbreaks and $76 \%$ of countries having a robust one [22]. Collectively, many LICs and MICs struggle to sustain or develop national preparedness capacities because of a lack of resources, competing investment priorities, and insufficient healthcare workers.

Assessments of preparedness have improved significantly over the past decade but actions to address these gaps require improvement. Supported by expertise from HICs, LICs and MICs have been significantly more proactive in building National Action Plans for Health Security (NAPHS) to improve preparedness. In 2016, Tanzania became the first country globally to develop and approve an USD 87 million NAPHS [24]. Working with the WHO, the U.S. Centers for Disease and Infection Control (CDC), the World Bank, and other development partners, Tanzania drafted a 5-year plan to address the weaknesses identified in its JEE and, crucially, costed the plan and assigned political leaders. This process of assigning monetary values to each preparedness activity triggers the mobilization of funding and establishes political will. Approximately half of countries with JEEs have an NAPHS and most have costed them. Despite this, no NAPHS is completely financed as of 2019 and most LICs cannot fund them from domestic resources alone [25].

Beyond a lack of expertise, insufficient and inefficient financing severely limit improvements in pandemic preparedness. The 2018 IDA budget of USD 75 billion met targets to support preparedness plans in 25 countries [21]. Yet, given trade-offs with other development priorities, many resource-constrained countries may opt not to spend their limited IDA envelope on health system preparedness [21]. As an example of competing priorities, Botswana has an HIV incidence of $25 \%$ and therefore spends $40 \%$ of its total healthcare expenditure on HIV/AIDS care [26]. Pathogen surveillance and antimicrobial resistance can be low priority compared with other more pressing development needs. Corruption further depletes already limited budgets, costing at least $10-25 \%$ of global health spending [27]. Paired with a lack of political commitment, health systems in some LICs and MICs can be chronically underfunded.

Resource-constrained countries remain highly dependent on financing by the $\mathrm{WHO}, \mathrm{HICs}$, and development partners for preparedness. This spending can be inefficient and ill-suited to LIC and MIC needs. The WHO is underfunded, with $80 \%$ of its budget being voluntary and highly earmarked [21]. Its financing mechanisms for pandemics, the Contingency Fund for Emergencies and Pandemic Emergency Financing, are either depleted or in need of reform [25]. With limited financial resources of its own, the WHO can link donors with countries to fund preparedness plans, a role codified in Article 44 of the IHR (1). This takes the form of the WHO's Global Health Cluster of 900 partners and the WHO Strategic Partnership for IHR and Health Security (SPH), founded in 2015 [28, 29]. SPH recently created an online tool to document 2366 investments by 62 donors [29]. These activities have yet to be examined for inefficiencies and are not centrally coordinated. Addressing
A

13 IHR (2005) Core Capacities

Legislation and Financin

Health Service Provision

Food Safety

Zoonotic Events

Laboratory

Chemical Events

Surveillance

Radiation Emergencies

Human Resources

Points of Entry

Risk Communication

National IHR Focal Points and IHR Coordination

National Health Emergency Framework

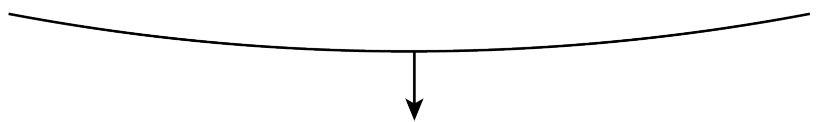

Average scores from self-assessments

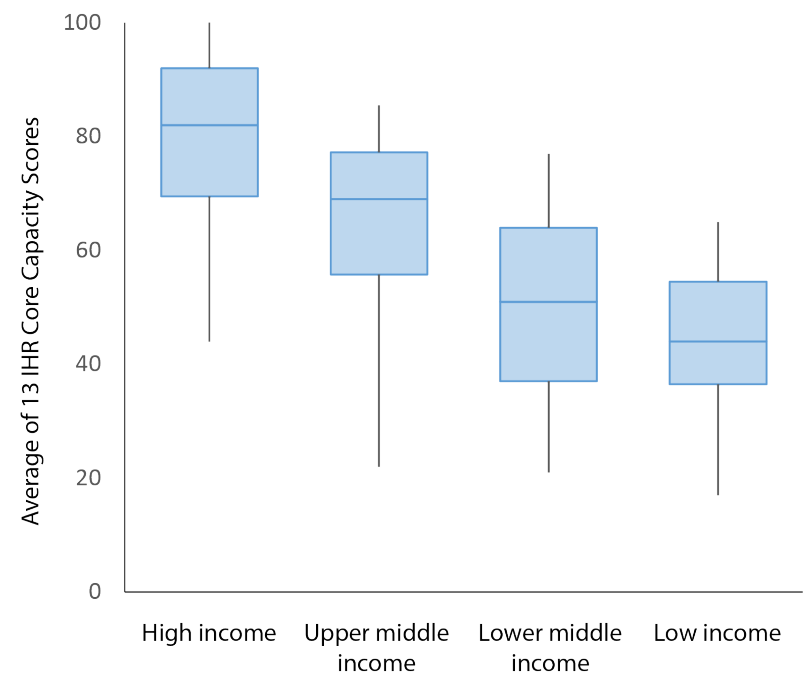

B

Complete Joint External Evaluation (JEE)

Develop National Action Plan for Health Security (NAPHS)

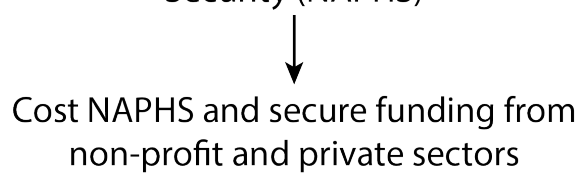

Figure 2: A - Average score for 13 IHR core health system capacities by income group. Y-axis represents the average percentage of health system capacity. The box plot shows the range of scores across $60 \mathrm{HICs}, 54 \mathrm{UMICs}, 49 \mathrm{LMICs}$, and 29 LICs. Source: WHO SDG Indicator 3.d.1, IHR Spar Average, 2019. B - Process of evaluating and improving national health capacities.

the fragmented funding system is a major opportunity area for HICs to improve preparedness beyond their borders.

Each HIC and development partner independently selects its own investment targets. Thus, highly visible activities with 
immediate returns (i.e. surveillance) are often prioritized over strengthening health systems [30]. Despite good intentions, new donor-driven surveillance networks can be poorly coordinated, redundant, and less beneficial to pandemic preparedness than simple measures strengthening overall health systems, as observed in pilot initiatives in India, South Africa, Tuvalu, and Cambodia [30]. Development partners and the WHO recommend that assistance for pandemic preparedness be catalytic and focus on activities that improve core health capacities. Prioritizing and coordinating investments in health systems to meet the IHR offers a high cost-benefit ratio. An annual investment of USD 1.9-3.4 billion would yield a global public health benefit of USD 30 billion, a 10:1 return on investment $[31,32]$. HICs stand to benefit from improving LIC and MIC preparedness capacities and systems.

Collectively, political will, targeted financial investments, and strengthened health systems successfully improve pandemic preparedness. For example, before the 2014-2016 Ebola outbreak, Nigeria implemented a preparedness plan that enabled quicker and less expensive control than its neighbors [33]. Similarly, India's health system improvements allowed it to identify and contain a Nipah virus outbreak in May of 2018 [34]. Both of these examples serve as models of improving preparedness in LICs and MICs through political commitment and active partnerships with HICs and development partners. Broadened to all LICs and MICs, a coordinated effort could ensure all countries reach a minimum preparedness standard. As further reading from this review, the Independent Panel for Pandemic Preparedness and Response released a report in May 2021 to document the development of COVID-19 into a global crisis and recommendations for future action. Further, 25 heads of government and international agencies recently called for the creation of an international pandemic treaty to build a more robust global health architecture [35].

\section{Conclusions}

The COVID-19 pandemic illustrates the risk of infectious pathogens. To minimize the risk of similar outbreaks, pandemic preparedness can be regarded as a global rather than national objective. Establishing a minimum global standard of preparedness involves prioritizing health system improvement and improving cooperation between HICs, MICs, LICs, and international organizations such as the WHO. Our review confirms that all countries have opportunities to improve preparedness and that the current framework for global health security, the IHR, can serve as a foundation. Post-COVID-19, we have the opportunity of improving our approach to pandemic preparedness. Global preparedness is only as strong as its weakest link.

\section{Acknowledgements}

The authors would like to thank the members of the Birnbaum group (Massachusetts Institute of Technology) and the Dushek group at the Sir William Dunn School of Pathology (University of Oxford).

\section{Citation}

Siller-Farfán, J. A. \& Gaglione, S. Unifying global pandemic preparedness efforts. MIT Science Policy Review 2, 76-81 (2021). https://doi.org/10.38105/spr.apzi6agz1h.

\section{Open Access}

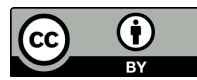

This MIT Science Policy Review article is licensed under a Creative Commons Attribution 4.0 International License, which permits use, sharing, adaptation, distribution and reproduction in any medium or format, as long as you give appropriate credit to the original author(s) and the source, provide a link to the Creative Commons license, and indicate if changes were made. The images or other third party material in this article are included in the article's Creative Commons license, unless indicated otherwise in a credit line to the material. If material is not included in the article's Creative Commons license and your intended use is not permitted by statutory regulation or exceeds the permitted use, you will need to obtain permission directly from the copyright holder. To view a copy of this license, visit http://creativecommons.org/licenses/ by $/ 4.0 /$

\section{Legislation Cited}

(1) International Health Regulations, May 23, 2005, https://www . who.int/publications/i/item/9789241580496.

(2) The Health Protection Agency (Amendment) Regulations 2007, SI 2007/1624, https://www.legislation.gov.uk/uksi/ 2007/1624/regulation/1/made.

(3) Règlement Sanitaire International (2005), June 18, 2007, no183/2007, M. B., p. 33326, http://www.ejustice. just. fgov.be/mopdf/2007/06/18_3.pdf.

\section{References}

[1] Nuclear Threat Initiative and Hopkin's Center for Health Security. Global Health Security Index (2019). Online: https://www.ghsindex.org/wp-content/uploads/ 2020/04/2019-Global-Health-Security-Index.pdf. Accessed: July, 2021.

[2] The World Bank. World Bank Country and Lending Groups (2021). Online: https://datahelpdesk.worldbank. org/knowledgebase/articles/906519-world-bankcountry-and-lending-groups. Accessed: July, 2021.

[3] Brown, T. M., Cueto, M. \& Fee, E. The World Health Organization and the transition from 'international' to 'global' health. American Journal of Public Health 96, 62-72 (2006). https: / / doi . org/ 10.2105/AJPH.2004.050831.

[4] The World Bank. Tracking universal health coverage: 2017 Global Monitoring Report (2017). Online: https://documents1.worldbank.org/curated/en/ 640121513095868125/pdf/122029-WP-REVISEDPUBLIC. pdf. Accessed: July, 2021.

[5] United Nations. Sustainable Development Goals (2021). Online: https://unstats.un.org/sdgs. Accessed: July, 2021.

[6] The World Bank. From panic and neglect to investing in health security: financing pandemic preparedness at a national level (2017). Online: http://documents1.worldbank. org/curated/en/979591495652724770/pdf/115271 REVISED-FINAL-IWG-Report-3-5-18.pdf. Accessed: July, 2021.

[7] Roser, M., Ritchie, H., Ortiz-Ospina, E. \& Hasell, J. Coronavirus Pandemic (COVID-19). Our World in Data (2020). Online: https://ourworldindata.org/coronavirus. Accessed: July, 2021.

[8] U.S. Bureau of Economic Analysis. Gross Domestic Product, 4th Quarter and Year 2020 (Advance Estimate) (2021). Online: https://www.bea.gov/news/2021/gross-domestic- 
product-4th-quarter-and-year-2020-advanceestimate. Accessed: July, 2021.

[9] Adhanom, T. WHO Director-General's opening remarks at the technical briefing on 2019 novel coronavirus (2020). Online: https://www. who.int/directorgeneral/speeches/detail/who-director-general-sopening-remarks-at-the-technical-briefing-on2019-nove1-coronavirus. Accessed: July, 2021.

[10] Keogh-Brown, M. R. \& Smith, R. D. The economic impact of SARS: how does the reality match the predictions? Health Policy 88, 110-120 (2008). https://doi.org/10.1016/j. healthpol.2008.03.003.

[11] Tejpar, A. \& Hoffman, S. J. Canada's violation of international law during the 2014-16 Ebola outbreak. Canadian Yearbook of International Law 54, 366-383 (2017). https: / / doi .org/ 10.1017/cyl.2017.18.

[12] Lillywhite, L. International Health Regulations must overcome perceptions of double standard. Chatham House (2016). Online: https: / /www. chathamhouse.org/ 2016/05/international-health-regulations-mustovercome-perceptions-double-standard. Accessed: July, 2021.

[13] Bajardi, P. et al. Human mobility networks, travel restrictions, and the global spread of $2009 \mathrm{H} 1 \mathrm{~N} 1$ pandemic. PLOS ONE 6, e16591 (2011). https://doi.org/10.1371/journal. pone. 0016591.

[14] Wells, C. R. et al. Impact of international travel and border control measures on the global spread of the novel 2019 coronavirus outbreak. Proceedings of the National Academy of Sciences 117, 7504-7509 (2020). https: / / doi .org/10.1073/pnas. 2002616117.

[15] World Health Organization. Report of the review committee on the role of the International Health Regulations (2005) in the Ebola outbreak and response (2016). Online: https: / /apps . who.int/gb/ebwha/pdf_files/WHA69/A69_21-en.pdf. Accessed: July, 2021.

[16] World Health Organization. WHO presence in countries, territories and areas (2019). Online: https: / / apps . who. int / iris/handle/10665/311592. Accessed: July, 2021.

[17] World Health Organization. Report of the review committee on the functioning of the International Health Regulations (2005) in relation to pandemic (H1N1) 2009 (2011). Online: https://apps.who.int/gb/ebwha/pdf_files/WHA64/ A64_10-en.pdf. Accessed: July, 2021.

[18] World Health Organization. Pandemic influenza preparedness framework for the sharing of influenza viruses and access to vaccines and other benefits (2011). Online: https://apps.who.int/gb/pip/pdf_files/pandemicinfluenza-preparedness-en.pdf. Accessed: July, 2021.

[19] World Health Organization. International Health Regulations (2005): Toolkit for implementation in national legislation: questions and answers, legislative reference and assessment tool and examples of national legislation (2009). Online: https://www.who.int/ihr/Toolkit_Legislative_ Implementation.pdf. Accessed: July, 2021.

[20] Taylor, A. L. et al. Solidarity in the wake of COVID-19: reimagining the International Health Regulations. The Lancet 396, 82-83 (2020). https://doi.org/10.1016/s0140$6736(20) 31417-3$.

[21] Global Preparedness Monitoring Board. A world at risk: annual report on global preparedness for health emergencies (2019). Online: https://www.preventionweb.net/ publications/view/67706http://apps.who.int/iris. Accessed: July, 2021.

[22] Kandel, N., Chungong, S., Omaar, A. \& Xing, J. Health security capacities in the context of COVID-19 outbreak: an analysis of International Health Regulations annual report data from 182 countries. The Lancet 395, 1047-1053 (2020). https: / / doi. org/10.1016/s0140-6736(20)30553-5.
[23] Talisuna, A. et al. Joint external evaluation of the International Health Regulation (2005) capacities: Current status and lessons learnt in the WHO African region. BMJ Global Health 4, e001312. https://doi.org/10.1136/bmjgh-2018-001312.

[24] Mghamba, J. M. et al. Developing a multisectoral National Action Plan for Health Security (NAPHS) to implement the International Health Regulations (IHR 2005) in Tanzania. BMJ Global Health 3, e000600 (2018). https://doi.org/10.1136/bmjgh2017-000600.

[25] Global Preparedness Monitoring Board. Thematic paper on the status of country preparedness capacities (2019). Online: https://apps.who.int/gpmb/assets/thematic papers/tr-2.pdf. Accessed: July, 2021

[26] Health Policy Project. Health financing profile: Botswana (2016). Online: https://www.healthpolicyproject.com/pubs / 7887 /Botswana_HFP.pdf. Accessed: July, 2021.

[27] García, P. J. Corruption in global health: the open secret The Lancet 394, 2119-2124 (2019). https://doi.org/10. $1016 /$ S $0140-6736$ (19) 32527-9.

[28] World Health Organization. WHO | Health cluster. Online: https://www.who.int/health-cluster/about/en/. Accessed: July, 2021.

[29] World Health Organization. WHO | Strategic partnership for health security and emergency preparedness (SPH). Online: https://extranet.who.int/sph/about-us. Accessed: July, 2021.

[30] Calain, P. From the field side of the binoculars: a different view on global public health surveillance. Health Policy and Planning 22, 13-20 (2007). https://doi.org/10.1093/ heapol/czlo35.

[31] The World Bank. People, pathogens and our planet: the economics of one health (2012). Online: http://hdl. handle. net/10986/11892. Accessed: July, 2021.

[32] Schar, D. L., Yamey, G. M., Machalaba, C. C. \& Karesh, W. B. A framework for stimulating economic investments to prevent emerging diseases. Bulletin of the World Health Organization 96, 138-140 (2018). https://doi.org/10.2471/BLT.17. 199547.

[33] Musa, E., Nasidi, A., Shuaib, F., Nguku, P. M. \& Vaz, R. G. Nigeria's Ebola outbreak response: lessons for future epidemic preparedness. Archives of Medicine 08 (2016). https : / / doi. org/10.21767/1989-5216.1000171.

[34] Arunkumar, G. et al. Outbreak investigation of Nipah virus disease in Kerala, India, 2018. The Journal of Infectious Diseases 219, 1867-1878 (2019). https://doi.org/10. 1093 /infdis/jiy612.

[35] World Health Organization. COVID-19 shows why united action is needed for more robust international health architecture (2021). Online: https://www.who.int/newsroom/commentaries/detail/op-ed---covid-19shows-why-united-action-is-needed-for-morerobust-international-health-architecture. Accessed: July, 2021. 